\title{
Update on imatinib for gastrointestinal stromal tumors: duration of treatment
}

This article was published in the following Dove Press journal:

OncoTargets and Therapy

29 July 2013

Number of times this article has been viewed

\author{
Mark Linch ${ }^{1,2}$ \\ Jeroen Claus ${ }^{2}$ \\ Charlotte Benson' \\ 'Sarcoma Unit, Royal Marsden \\ Hospital, ${ }^{2}$ Protein Phosphorylation \\ Laboratory, Cancer Research UK \\ London Research Institute, London, \\ United Kingdom
}

\begin{abstract}
Gastrointestinal stromal tumors (GISTs) are the most common sarcoma of the gastrointestinal tract, with transformation typically driven by activating mutations of $c$-KIT and less commonly platelet-derived growth factor receptor alpha (PDGFRA). Successful targeting of c-KIT and PDGFRA with imatinib, a tyrosine kinase inhibitor (TKI), has had a major impact in advanced GIST and as an adjuvant and neoadjuvant treatment. If treatment with imatinib fails, further lines of TKI therapy have a role, but disease response is usually only measured in months, so strategies to maximize the benefit from imatinib are paramount. Here, we provide an overview of the structure and signaling of c-KIT coupled with a review of the clinical trials of imatinib in GIST. In doing so, we make recommendations about the duration of imatinib therapy and suggest how best to utilize imatinib in order to improve patient outcomes in the future.

Keywords: adjuvant, c-KIT, mutations, resistance, treatment, gastrointestinal stromal tumors, imatinib
\end{abstract}

\section{Introduction}

Gastrointestinal tumors (GIST) are mesenchymal tumors thought to be derived from interstitial cells of Cajal that coordinate peristalsis within the gastrointestinal tract, and occur most commonly in the stomach. The incidence of GIST is approximately 15 per million per year. ${ }^{1}$ Immunohistochemically, most GISTs show positive staining for c-KIT (CD117 antigen), DOG1, CD34, and PKC $\theta$, and on mutational analysis have characteristic activating mutations in $c-K I T$ or PDGFRA. The mainstay of treatment for localized GIST is surgical resection. GIST has been shown to be chemotherapy-insensitive, so patients with inoperable or advanced GIST had a dismal prognosis before imatinib was developed. Imatinib, previously known as STI571, is an adenosine triphosphate (ATP)-competitive inhibitor of tyrosine protein kinases. It was the product of a rational drug development program for inhibitors against $B c r-A b l$, the proto-oncogene identified to be the driver for chronic myeloid leukemia, and was an emphatic success. ${ }^{2,3}$ In addition, imatinib was shown to inhibit c-KIT in mast cell leukemia harboring an activating mutation of $c-K I T,{ }^{4}$ and inhibition of growth in the first GIST cell line, GIST882, was subsequently demonstrated. ${ }^{5}$ These combined findings led rapidly to a compassionate use program in patients with GIST. The first patient with GIST to be treated with imatinib was a 50-year-old lady who had rapidly progressing disease with liver and intra-abdominal metastasis, and was found to carry an exon 11 activating mutation of $c$-KIT. Within four weeks of starting imatinib, her liver lesions had significantly reduced and there was a complete metabolic response by fluorodeoxyglucose positron emission tomography criteria. ${ }^{6}$
Correspondence: Charlotte Benson Sarcoma Unit, Royal Marsden Hospital, Fulham Road, London, SW3 6J],

United Kingdom

Tel +442078082200

Fax +44207808 2113

Email charlotte.benson@rmh.nhs.uk 
Subsequently, imatinib has become the first-line treatment for locally advanced/metastatic GIST and as adjuvant or neoadjuvant therapy. Most patients eventually cease to benefit from imatinib, and treatment with second-line and third-line tyrosine kinase inhibitors is used. A critical question remains as to what is the appropriate duration of imatinib therapy in these different contexts. The duration of successful treatment depends on efficacy and tolerability. In this review, we provide a structure-functional analysis of the most prevalent imatinib target, c-KIT, and combine this with clinical trial data to provide an overview of the activity, resistance, and tolerability of imatinib, and thus the optimal duration of imatinib treatment.

\section{Structure and signaling of c-KIT Structure of c-KIT}

The viral oncogene $v-c-K I T$ was first identified as the transforming gene of Hardy-Zuckerman 4 feline sarcoma virus in 1986. ' Soon afterwards, the cellular homolog, $c-K I T$, was cloned, and found to be located on chromosome $4 \mathrm{q} 11$ comprising 21 exons. $^{8} \mathrm{c}$-KIT is a transmembrane receptor tyrosine kinase that is normally activated by engagement of stem cell factor with the extracellular domain (in part coded for by exon 9) of the receptor, resulting in homodimerization. The dimerization results in transphosphorylation of multiple tyrosine (Y) residues, ${ }^{9}$ leading to allosteric activation of the kinase and formation of phosphotyrosine-containing protein binding sites.

Like many protein kinases, c-KIT has a bilobed kinase domain, with the pockets for substrate and ATP binding (catalytic site, coded for by exons 13 and 14) lying between the two lobes (Figure 1A). ${ }^{10}$ The lobes are able to move relative to each other, opening or closing the catalytic site, and this movement can be defined by the relative positions of the $\alpha-C$ helix. The glycine-rich loop (G-loop), the catalytic lysine (K), and the activation loop (A-loop) are key for the positioning of ATP and subsequent transfer of a phosphate group to the substrate. The juxtamembrane region, which is coded by exon 11 , is autoinhibitory and maintains the closed kinase position. Upon transphosphorylation of the juxtamembrane region, the kinase can adopt the open active state which is further stabilized by transphosphorylation of the A-loop, a sequence coded for by exons 17 and 18 .

At the start of the A-loop is an aspartate (D), phenylalanine (F), and glycine (G) sequence (DFG motif) which, when the A-loop is in its phosphorylated activated state, has the F811 (F of the DFG) facing inwards (so-called "DFG-in") to the nucleotide binding pocket and helping to coordinate
A
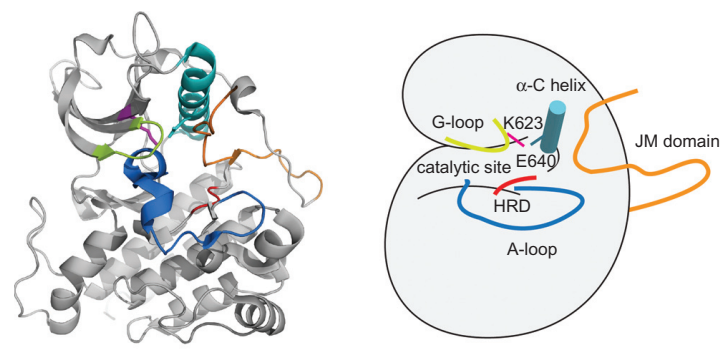

B
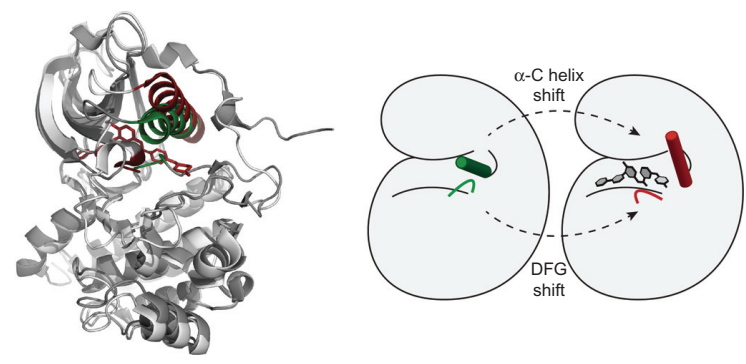

Figure I Structural features of the catalytic c-KIT domain. (A) Inactive conformation of the c-KIT kinase domain (PDB code IT45) with important motifs highlighted. The catalytic site is bordered by a variety of motifs required for activity. The glycine-rich loop (lime), HRD-motif (red), and K623 (pink) coordinate adenosine triphosphate binding and phosphotransfer. There is a charged interaction between K623 and E640 in the $\alpha-C$ helix (teal) that helps stabilizes the conformation. Because the inhibitory juxtamembrane (JM) region is bound (orange), the A-loop (blue) is in an "out" position. (B) Imatinib binds the inactive conformation of c-KIT (PDB codes IT45 and IT46). Compared with the active state (green), the imatinib-bound structure of c-KIT (red) has a shift of the $\alpha-C$ helix and DFG-motif to form an inactive conformation of the kinase.

ATP binding (Figure 1B). In the dephosphorylated inactive A-loop state, the F811 faces away from the nucleotide binding pocket, and it is this form that imatinib binds to and stabilizes, thus sustaining an inactive kinase. ${ }^{11,12}$

\section{c-KIT-activating and imatinib-desensitizing mutations}

Many $c$-KIT mutations have been linked to oncogenic transformation or imatinib resistance, and these mutations are localized on a number of hot spots within the c-KIT protein, namely exons 9, 11, 13, and 17 (Figure 2). Up to $85 \%$ of GIST samples taken at the time of diagnosis carry mutations in $c$-KIT, most commonly in exons 9 and 11, that tend to confer constitutive activation and imatinib sensitivity. In contrast, mutations of exons 13 and 17 (nucleotide binding pocket and A-loop) tend to cause imatinib insensitivity, which can occur de novo but are usually identified in patients who have progressed on treatment after an initial response. Therefore, molecular characterization of $c$-KIT in GIST patients provides useful information on imatinib sensitivity, an explanation for resistance, and may help guide imatinib dosing and scheduling, although there is still much unknown (Table 1). 


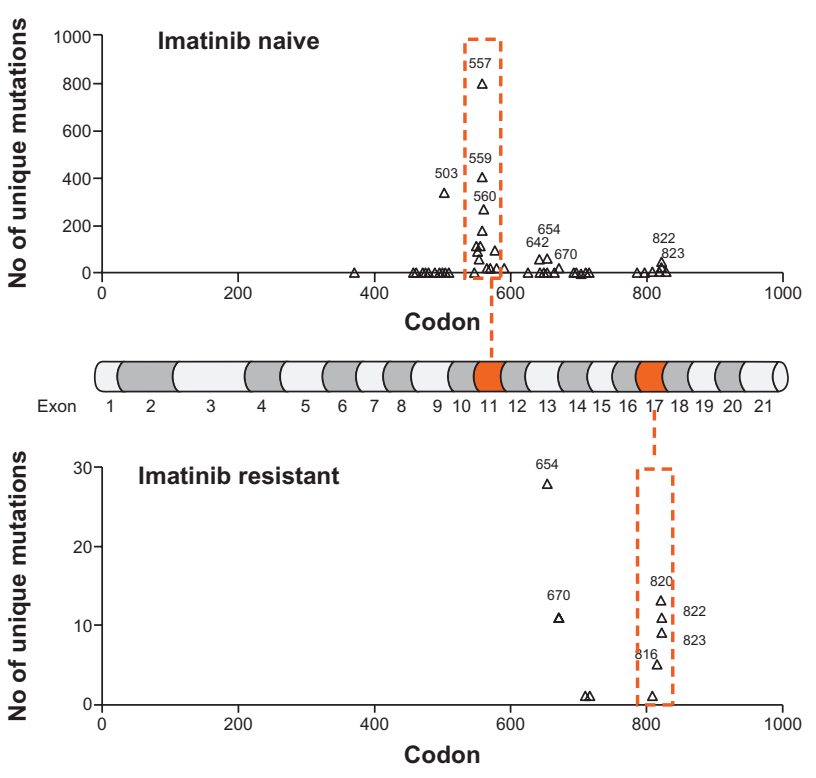

Figure 2 Relative frequency of c-KIT mutations in gastrointestinal stromal tumors. Top panel shows the relative frequency of mutations in treatment-naïve patients. Where the mutation results in more than one amino acid substitution/ deletion/insertion, the most $\mathrm{N}$-terminal residue is denoted. The total number of gastrointestinal stromal tumor samples in this data set is 7254 for which there were 3903 unique mutated samples. Mid-panel shows mRNA of c-KIT denoting the 21 exons. Lower panel shows the relative frequency of mutations in patients who had progressed on imatinib. Two exon hot spots are highlighted with a dotted orange line.

\section{c-KIT-binding domains and signaling}

$\mathrm{c}-\mathrm{KIT}$ is able to participate in multiple signaling pathways by recruiting adaptor proteins and phosphorylating substrates, some of which are themselves kinases. In this way, there is activation of signal transduction leading to biological responses, including cell survival, migration, and proliferation. ${ }^{13}$ Important proximal c-KIT-interacting proteins include Src family kinases, the regulatory subunit of PI3K (p85), phospholipase $\mathrm{C} \gamma$, and several adaptor proteins, such as Grb2, Grb7 and APS. ${ }^{14,15}$ Common to each of these proteins is at least one of the following protein-binding domains that mediate the interaction with tyrosine phosphorylated c-KIT protein, ie, a pleckstrin homology, Src homology 2, or Src homology 3, as reviewed by Roskoski. ${ }^{14}$ Immunohistochemistry and gene profiling of GIST primary tumors and cell lines combined with studies of chemical inhibition of c-KIT have helped to identify c-KIT-dependent signal transduction pathways (Table 2). Further, inhibition of these identified signaling targets has demonstrated anticancer phenotypes in cell lines and mouse cancer models (Table 3). Promising drugs for c-KIT signaling targets have been taken forward and tested in combination with imatinib in early clinical trials.

\section{Imatinib in advanced GIST Duration of imatinib therapy is determined by efficacy}

The maximum tolerated dose of imatinib (400 mg twice daily) was demonstrated in a Phase I European Organisation for Research and Treatment of Cancer (EORTC) trial, ${ }^{16}$ and activity was confirmed in two Phase II trials with overall response rates of $63 \%-73 \%$ (see Table 4 for individual trial details). ${ }^{17,18}$ In fact, the results were so much better than for historical controls treated with chemotherapy that the subsequent Phase III trials were required to include imatinib in the control arms, so two different daily doses (400 mg and $800 \mathrm{mg}$ ) were compared. In both the European-Australasian trial and the North American Intergroup study, response rates were similar between the high-dose and low-dose imatinib arms, with a progression-free survival of approximately 18-24 months. ${ }^{19,20}$ In the European-Australasian trial, but not the North American Intergroup study, there was a statistically significant improvement in progression-free survival with the higher dose of imatinib, ${ }^{19}$ and with extended follow-up, the progression-free survival was 22 months. ${ }^{21} \mathrm{~A}$ pooled meta-analysis of these two trials demonstrated a small but significant improvement in progression-free survival in the high-dose arm (19 months versus 23 months, hazards ratio $0.89, P=0.0195$ ) but no difference in overall survival. ${ }^{22}$ When the duration of response was analyzed for the common mutation subgroups, progression-free survival was longest for exon 11 mutations at 36 months and less favorable for exon 9 mutations or patients lacking both $c-K I T$ and $P D G F$ mutations, ie, the so-called wild-type variant. ${ }^{22}$

\section{Prolongation of imatinib therapy by dose escalation}

Acquired resistance to imatinib can result as a consequence of amplification of $c-K I T$, new secondary mutations, or switching to distinct protumorigenic signaling pathways. ${ }^{23}$ From a understanding of enzyme kinetics, amplification of the $c-K I T$ gene and thus high expression of the c-KIT protein kinase would be predicted to require higher concentrations of inhibitor, although whether such tumors respond to higher-dose imatinib has not been confirmed by clinical data. Additionally, in silico modeling has predicted that the binding affinity of imatinib to the nucleotide binding pocket of exon 9-mutated c-KIT would be lower but might be subverted by dose escalation. ${ }^{24}$ Clinical data from the EORTC and North American Intergroup studies, where patients were allowed to cross over to high-dose imatinib upon progression, revealed that approximately one 
Table I Selected imatinib sensitizing and desensitizing mutations of c-KIT

\begin{tabular}{|c|c|c|c|c|c|}
\hline Exon & Domain & Amino acids & Consequence & Structural rationale & Reference \\
\hline \multicolumn{6}{|c|}{ Activating } \\
\hline Exon 9 & Extracellular & $502-503$ & Activation & Undergoes constitutive oligomerization & Lux et $\mathrm{a}^{69}$ \\
\hline Exon II & JM & Deletion 555-557 & $\begin{array}{l}\text { Tends to confer constitutive activation } \\
\text { and correlate with high response rates } \\
\text { to imatinib }\end{array}$ & $\begin{array}{l}\text { Modeling has demonstrated that the } \\
\text { JM domain induced steric hindrance at } \\
\text { entrance to nucleotide binding pocket }\end{array}$ & $\begin{array}{l}\text { Miettinen et } \mathrm{al}^{70} \\
\text { Pierotti et } \mathrm{al}^{23}\end{array}$ \\
\hline Exon II & $\mathrm{JM}$ & W557G/Y578C & $\begin{array}{l}\text { Constitutively active and imatinib- } \\
\text { sensitizing mutational combination }\end{array}$ & Release of JM steric hindrance & Conca et $\mathrm{al}^{71}$ \\
\hline Exon 13 & NBP & K642E substitution & $\begin{array}{l}\text { Activating, found as a germ-line } \\
\text { mutation }\end{array}$ & Charge reversal (positive to negative) & Roskoski et al ${ }^{72}$ \\
\hline \multicolumn{6}{|c|}{ Imatinib-desensitizing mutations } \\
\hline Exon II & $\mathrm{JM}$ & $\begin{array}{l}\text { L576P } \\
\text { (Rare) }\end{array}$ & Insensitive to imatinib & $\begin{array}{l}\text { Computer modeling suggests that } \\
\text { L576P/KIT is two times less sensitive } \\
\text { than the wild-type counterpart }\end{array}$ & Conca et $\mathrm{al}^{73}$ \\
\hline Exon 14 & NBP & T670I & Resistance to imatinib & $\begin{array}{l}\text { Gatekeeper residue to a hydrophobic } \\
\text { back pocket. Access of imatinib to } \\
\text { back pocket hindered by substitution } \\
\text { to isoleucine }\end{array}$ & Tamborini et $\mathrm{al}^{74}$ \\
\hline Exon 14 & NBP & V654A & Resistance to imatinib & Steric hindrance of imatinib binding & Tamborini $^{24}$ \\
\hline Exon 17 & A-loop & $\mathrm{D} 816 \mathrm{~V}$ & Activating and imatinib insensitive & $\begin{array}{l}\text { Predicted DFG in that IM is unable } \\
\text { to bind }\end{array}$ & Pierotti et $\mathrm{a}^{23}$ \\
\hline Exon 17 & A-loop & D820N & Activating and imatinib-insensitive & $\begin{array}{l}\text { Predicted DFG in that IM is unable } \\
\text { to bind }\end{array}$ & Pierotti et al ${ }^{23}$ \\
\hline Exon 17 & A-loop & T823D & Activating and imatinib-insensitive & $\begin{array}{l}\text { Unknown mechanism: in vitro } \\
\text { autophosphorylation studies suggest } \\
\text { that this is a kinase-dead mutant }\end{array}$ & DiNitto et al ${ }^{9}$ \\
\hline
\end{tabular}

Note: This is not an exhaustive list of mutations.

Abbreviations: JM, juxtamembrane; A-loop, activation loop; NBP, nucleotide binding pocket; IM, imatininb.

third of these patients were able to regain disease control. The median progression-free survival following crossover to high-dose imatinib was three and five months in the Phase III EORTC and North American Intergroup trials, respectively. 25,26 Subsequent analysis has demonstrated that the patients who responded to this dose escalation were indeed those that carried exon 9 mutations and often demonstrated primary resistance (progression in $\leq 3$ months from initiation of imatinib). ${ }^{27}$
Based on these data, a high dose of $800 \mathrm{mg}$ /day should only be recommended routinely for patients who carry the exon 9 activating mutation.

\section{Biomarker-driven prolongation of treatment}

The EORTC investigated the pharmacokinetics of imatinib in patients with advanced GIST who were enrolled into their

Table 2 c-KIT signaling molecules downstream

\begin{tabular}{|c|c|c|c|}
\hline Technique & Model & Targets identified & Reference \\
\hline Immunohistochemistry & Human GIST tumors & $\begin{array}{l}\text { MAPK } \\
\text { AKT } \\
\text { P70S6K }\end{array}$ & Duensing et $\mathrm{al}^{75}$ \\
\hline Immunohistochemistry & $\begin{array}{l}\text { Human GIST cell lines treated } \\
\text { with imatinib }\end{array}$ & MAPK p42/44 (part of Ras $>$ Raf $>$ MEK $>$ Erk signaling axis) & Duensing et $\mathrm{al}^{75}$ \\
\hline Immunohistochemistry & $\begin{array}{l}\text { Imatinib treatment of transgenic } \\
\text { GIST mice }\end{array}$ & $\begin{array}{l}\text { PI3K/Akt (PDKI, AKT, mTOR, GSK3, p70S6K, and 4EBPI), } \\
\text { STAT3, and STAT5 pathways }\end{array}$ & Rossi et $\mathrm{al}^{76}$ \\
\hline Gene profiling & Human GIST tumors & KIT, PRKCQ, PIK3CB, FGF2, ETVI and IGF2 & $\begin{array}{l}\text { Baird et } \mathrm{al}^{77} \\
\text { Francis et } \mathrm{al}^{78}\end{array}$ \\
\hline Gene profiling & $\begin{array}{l}\text { Imatinib treatment of transgenic } \\
\text { GIST mice }\end{array}$ & $\begin{array}{l}\text { I } 24 \text { genes differentially expressed: } \\
\text { increased; CDKN2C decreased; } \\
\text { EIFIA and genes involved in interferon response }\end{array}$ & Rossi et $\mathrm{al}^{76}$ \\
\hline $\begin{array}{l}\text { Copy number and gene } \\
\text { expression data }\end{array}$ & Human GIST tumors & $\begin{array}{l}\text { WNT7/ } \beta \text {-catenin pathways, apoptotic pathways, heat shock } \\
\text { proteins, ubiquitination factors, and histone deacetylases }\end{array}$ & Astolfi et $\mathrm{al}^{79}$ \\
\hline
\end{tabular}

Abbreviation: GIST, gastrointestinal stromal tumor. 
Table 3 Phenotypic effects of inhibition of signaling pathways associated with c-KIT

\begin{tabular}{|c|c|c|c|c|}
\hline Inhibitor & Inhibitor target & Model system & Phenotypic effect & Reference \\
\hline BKMI20 and BEZ & $\mathrm{PI} 3 \mathrm{~K}$ & GIST cell lines & Growth suppression & Li et al ${ }^{80}$ \\
\hline GDC-094I & $\mathrm{PI} 3 \mathrm{~K}$ & GIST cell line xenograft & $\begin{array}{l}\text { Delayed tumor growth reduced tumor } \\
\text { burden, sustained response }\end{array}$ & Floris et $\mathrm{a}^{81}$ \\
\hline RAD00I & mTOR & GIST cell lines and xenograft & $\begin{array}{l}\text { Decreased pAKT and decreased tumor } \\
\text { growth (FDG-PET) }\end{array}$ & $\begin{array}{l}\text { Rossi et } \mathrm{al}^{76} \\
\text { Chang et } \mathrm{a} \mathbf{8}^{82} \\
\text { Pantaleo et } \mathrm{a}{ }^{83}\end{array}$ \\
\hline PKC $\theta$ shRNA & $\mathrm{PKC} \theta$ & GIST cell lines & $\begin{array}{l}\text { Decreased proliferation, increased apoptosis } \\
\text { Decreased c-KIT protein }\end{array}$ & $\begin{array}{l}\text { Duensing et a }{ }^{84} \\
\text { Ou et } \mathrm{al}^{85}\end{array}$ \\
\hline I7-AAG & Hsp90 & GIST cell lines & Decreased proliferation, increased apoptosis & Bauer et $a^{86}$ \\
\hline ATI3387 & Hsp90 & GIST cell lines and xenograft & Decreased proliferation synergy with imatinib & Smyth et $a^{87}$ \\
\hline IPI-504 & Hsp90 & GIST cell line xenograft & $\begin{array}{l}\text { Tumor regression } \\
\text { Increased necrosis } \\
\text { More potent with imatinib }\end{array}$ & Floris et al ${ }^{88}$ \\
\hline LBH589 & HDAC & GIST cell lines & $\begin{array}{l}\text { Decreased proliferation } \\
\text { Reduced KIT mRNA } \\
\text { Acetylation of Hsp90 }\end{array}$ & Muhlenberg et $\mathrm{a}^{89}$ \\
\hline $\begin{array}{l}\text { SRI (monoclonal } \\
\text { antibody) }\end{array}$ & c-KIT & GIST cell lines and xenograft & Reduced growth & Edris et $\mathrm{a}^{90}$ \\
\hline
\end{tabular}

Abbreviations: GIST, gastrointestinal stromal tumor; FDG-PET, fluorodeoxyglucose positron emission tomography; HDAC, histone deacetylase; Hsp90, heat shock protein 90.

Phase I and Phase II studies analyzing the effect of covariates. From their modeling, low clearance was correlated with low body weight and high granulocyte count, and low hemoglobin was correlated with a low volume of distribution. Further, there was a trend towards a $33 \%$ increase in imatinib clearance after 12 months. ${ }^{28}$ Similarly, a post hoc analysis of a subset of 73 patients with advanced GIST in the US-Finnish Phase II trial treated daily with $400 \mathrm{mg}$ or $600 \mathrm{mg}$ imatinib, for whom data were available on plasma imatinib levels on days 1 and 29, was done to see if there was a correlation between drug exposure and clinical outcomes. Patients with a trough level of imatinib in the lower quartile were less likely to obtain clinical benefit (a composite endpoint of complete response, partial response, and stable disease) and had a decreased time to progression (lowest quartile versus other

Table 4 Landmark imatinib trials in patients with advanced gastrointestinal stromal tumors

\begin{tabular}{|c|c|c|c|c|c|}
\hline Phase & Sponsor & $\mathbf{n}$ & $\begin{array}{l}\text { PFS } \\
\text { (months) }\end{array}$ & $\begin{array}{l}\mathbf{R R} \\
\text { (\%) }\end{array}$ & Reference \\
\hline I & EORTC & 35 & $N R$ & $54 \%$ & $\begin{array}{l}\text { Van Oosterom } \\
\text { et } \mathrm{al}^{16}\end{array}$ \\
\hline \multirow[t]{2}{*}{ II } & US-Finland & 147 & 24 & $63 \%$ & Demetri et $\mathrm{al}^{17}$ \\
\hline & B2222 & & 29 & $68 \%$ & Blanke et $\mathrm{al}^{26}$ \\
\hline ॥ & EORTC & 27 & NR & $73 \%$ & Verweij et al ${ }^{18}$ \\
\hline III & $\begin{array}{l}\text { North American } \\
\text { Intergroup S0033 }\end{array}$ & 746 & $18-20$ & $45 \%$ & Blanke et $\mathrm{al}^{20}$ \\
\hline III & EORTC/ISG/AGITG & 946 & NR 22 & $52 \%$ & Verweij et al ${ }^{19}$ \\
\hline
\end{tabular}

Abbreviations: PFS, progression-free survival; RR, response rate; NR, not reported; EORTC, European Organisation for Research and Treatment of Cancer; ISG, Italian Sarcoma Group; AGITG, Australasian Gastrointestinal Trials Group. quartiles, 11.3 months versus $>30$ months, respectively; $P=0.003) .{ }^{29}$

Therefore, these retrospective studies raised the possibility that treatment failure on imatinib could be as a result of lowered plasma imatinib levels in a subset of patients. Eechoute et al designed a prospective study in 50 patients to identify causes of reduced imatinib pharmacokinetics and to test the exposure-outcome hypothesis. Full pharmacokinetic profiles were performed at day 1 and then at one, six, and 12 months, and trough imatinib levels were taken at day 14 and monthly thereafter. There was almost a $30 \%$ reduction in the plasma trough imatinib level in the first three months of treatment, after which clearance seemed to plateau. However, the explanation for this clearance remains elusive and it cannot be convincingly attributed to reduced absorption, increased liver metabolism, or an increase in drug efflux. ${ }^{30}$

Imatinib has been shown in vitro to reduce the proliferation and colony-forming capacity of hematopoietic progenitor cells (CD34+/CD38+) in both a c-KIT-dependent and c-KIT-independent manner. ${ }^{31}$ In keeping with this observation, patients with chronic phase myeloid leukemia treated with imatinib commonly exhibit a macroscopic anemia, ie, a high mean cell volume (MCV). ${ }^{32}$ Several groups have suggested that this rise in MCV correlates with response; for example, patients who had an elevated MCV ( $>100 \mathrm{fL})$ for at least six months were more likely to achieve a complete hematological response after 12 months of treatment with imatinib (increased MCV versus non-increased MCV; 
complete hematological response, $92.1 \%$ versus $69.6 \%$, respectively; $P=0.011){ }^{33}$

To assess whether elevated MCV as a predictive surrogate marker of imatinib response in chronic myeloid leukemia could be relevant in imatinib-treated patients with GIST, a preliminary retrospective analysis of 130 patients with locally advanced/advanced GIST treated with imatinib was performed at our institution. We found that 33 patients had $\mathrm{a} \geq 10 \%$ increase in MCV three months after initiation of imatinib, and in patients with $\mathrm{a} \geq 10 \%$ increase in $\mathrm{MCV}$, there was almost a $50 \%$ prolongation in progression-free survival compared with those who did not have such an increase (37.1 months versus 24.3 months, respectively; $P=0.032$ ). ${ }^{34}$ Based on the above evidence, it is plausible that MCV is also a biomarker for imatinib exposure. Therefore, using plasma imatinib and/or MCV measurements, it may be possible to identify patients in whom there is increased clearance and who may benefit from dose-escalation strategies, potentially prolonging time to treatment failure and thus the duration of imatinib therapy. This hypothesis needs testing in prospective randomized trials.

\section{Prolongation of imatinib treatment by intermittent dosing}

The most frequent cause of imatinib failure is acquired secondary resistance mutations or toxicity. To address whether acquired resistance to imatinib in patients with advanced GIST can be delayed, the French Sarcoma Group designed a Phase III trial (BFR-14) that randomized patients to continuous or interrupted imatinib treatment following one, three, or five years of benefit from imatinib. Patients who discontinued imatinib were considerably more likely to progress than patients who were on continuous dosing, and due to the large number of patients with progressive disease in the interruption group (12 of 25 patients versus one of 25 in the continuous group), the randomization was stopped. In the interruption arm, all patients who were subsequently rechallenged with imatinib had at least stable disease after three months and 12 of 21 had a partial response or better. However, the volume of disease remained greater in the interruption arm and there was no obvious difference between time to secondary resistance or overall survival, although this study was not powered to detect such a difference. ${ }^{35}$ A subsequent exploratory analysis of the BFR-14 trial was recently performed to identify predictive factors for progression-free survival during imatinib interruption and progression-free survival upon rechallenge with imatinib. The length of continuous imatinib before randomization (one, three, or five years) and the previous best response (complete response, partial response, or stable disease) correlated directly with progression-free survival once treatment was interrupted..$^{36}$ This is not surprising given that patients who were in the five-year group and/or had a complete response are essentially preselected as a biologically favorable subset. However, what is important to note is that all patients did eventually progress, telling us that viable GIST cells remain despite five years of treatment or a complete radiological response. Patients who progressed rapidly during interruption of imatinib were also more likely to have a short progression-free survival upon imatinib rechallenge, which probably reflects the biological characteristics of GIST, particularly in terms of acquired resistance. In summary, it would seem sensible to recommend continuous dosing of imatinib in the advanced setting. If patients are intolerant of imatinib despite dose modification, an argument could be made to cautiously adopt an interrupted dosing strategy.

\section{Prolongation of imatinib therapy by use of combination strategies}

Despite the success of imatinib as a single agent in the management of GIST, resistance is almost inevitable and there is a clear need for new agents with a different mode of action. Although new agents might be tested initially as single agents in imatinib-resistant patients, there is a strong rationale to identify treatments that synergize with imatinib in an attempt to prevent resistance. The ultimate goal of combining other treatments with imatinib is to prolong the treatment duration and potentially cure patients. Combination strategies have focused on targeting upregulated signaling pathways in imatinib-resistant patients or on reducing the stability of activated signaling proteins (see section on c-KIT binding domains and signaling).

Based on preclinical data in GIST cell models, the PI3K/ Akt/mTOR signaling axis has been studied in early clinical trials. An international dose-finding study for BKM120, a PI3K inhibitor, in combination with imatinib is currently in accrual. Perifosine, an inhibitor of AKT, in combination with imatinib had minimal activity in 40 patients with imatinibresistant GIST, although there was a suggestion that there may be a benefit in wild-type GIST. ${ }^{37}$ In a Phase I-II study of imatinib together with RAD001, an mTOR inhibitor, in patients resistant to imatinib, the combination was shown to be tolerable and to have activity. In the 47 pretreated patients taking part, there was one patient (2\%) with a partial response and 20 patients (43\%) with stable disease, and further studies are planned. ${ }^{38}$ 
The other main focus of clinical trials involving novel agents has been heat shock protein 90 and histone deacetylase inhibitors in combination with imatinib. In a Phase I trial of IPI-504, a heat shock protein 90 inhibitor, a 22\% partial response rate and $78 \%$ stable disease rate was seen in patients with imatinib-resistant GIST as assessed by positron emission and computed tomography. ${ }^{39}$ This led to a placebo-controlled Phase III trial which had to be terminated early due to 3 out of 4 deaths on treatment in the IPI-504 arm. ${ }^{40}$ Panobinostat (LBH589) is a histone deacetylase inhibitor that has been tested in combination with imatinib. At the maximum tolerated dose of $20 \mathrm{mg}$ three times weekly with imatinib $400 \mathrm{mg} /$ day, there were seven grade 3 adverse events, no objective responses by Response Evaluation Criteria In Solid Tumors, and one partial response based on metabolic criteria. ${ }^{41}$ In summary, while there have been a number of interesting mechanism-based combination drug studies with imatinib, disappointing efficacy or toxicity results have precluded their translation to clinical practice. This remains an area of intensive investigation, and further advances that may help prolong imatinib treatment and afford patient benefit are anticipated in the near future.

\section{Prolongation of imatinib treatment duration by local therapy}

Surgery has traditionally played a palliative role in the advanced disease setting. However, several single-institution studies have investigated the role of surgery as a part of multimodality management of advanced GIST. One of the rationales for resecting oligometastatic disease or single sites of progressive disease is to eliminate imatinib-resistant clones, leaving behind only sensitive disease and prolonging imatinib therapy.

In a retrospective single-institution analysis of 69 patients who underwent surgery for advanced GIST while being treated with tyrosine kinase inhibitors, it was demonstrated that there was an association between the presurgical treatment response status (stable disease, limited progression, or generalized progression) and 12-month progression-free survival $\left(80 \%, 33 \%\right.$, and $0 \%$, respectively). ${ }^{42}$ In two further studies, progression-free survival on imatinib following surgery for focal disease progression was eight and 11 months, which compares favorably with the outcomes seen in patients who are switched to sunitinib upon disease progression. ${ }^{43-45}$ These data would suggest that there is no role for elective surgery in patients with generalized progression on imatinib, but that resection of focally progressive disease could be considered to prolong the duration of therapy. However, randomized controlled trials are required to answer this question.
Radiofrequency ablation can also be used to treat metastatic lesions. In 13 imatinib-treated GIST patients with metastasis mainly to the liver, radiofrequency ablation was successful in $92 \%$ of cases, with a median progression-free survival of 28 months and minimal morbidity. ${ }^{46}$ More specifically, in a separate study of nine patients who had focal progression of metastatic disease in the liver or soft tissue (single or limited sites) on imatinib (or sunitinib) therapy and underwent percutaneous radiofrequency ablation, all patients had successful ablation of the targeted lesion, three patients remained stable post radiofrequency ablation after a median follow-up of 13.6 months on treatment, while six progressed systemically after a median of 4.7 months. ${ }^{47}$ These preliminary results point to a possible benefit of radiofrequency ablation as an adjunct to imatinib in order to prolong the duration of treatment in patients with focal progression.

\section{Imatinib in localized GIST Adjuvant imatinib}

Whilst surgery remains the key therapeutic maneuver for patients with primary GIST, the risk of recurrence following complete resection remains high. ${ }^{48}$ This is likely due to the persistence of microscopic disease following surgery. In 2001, a National Institutes of Health consensus group proposed a scheme to estimate the risk of metastatic disease following resection of the primary GIST based on primary tumor site, size, and mitotic rate. ${ }^{49}$ The Armed Forces Institute of Pathology in the US built upon this initial work, based on observation of 1784 patients, and categorized the risk of recurrence as low, intermediate, or high. ${ }^{48,50}$ Subsequently, a prospectively validated prognostic nomogram ${ }^{51}$ was developed to predict the risk of recurrence, which was shown to have improved accuracy and furthermore allowed prediction in individual patients rather than limited discrete categories. Most recently, the Scandinavian group developed prognostic contour maps to estimate the risk of recurrence using pooled data from 2560 patients. ${ }^{52}$ This work shows that size and mitotic rate are the two most important prognostic variables, but also highlights the importance of intraoperative tumor rupture as an adverse prognostic feature.

The high risk of recurrence following surgery and subsequent development of metastatic disease has led to exploration of the role of adjuvant imatinib in order to reduce the risk of recurrence, and initially, a number of single-arm and Phase II studies of adjuvant imatinib for a duration of 12-26 months suggested benefit. The American College of Surgeons Oncology Group did a large multicenter, 
randomized, double-blind, placebo-controlled Phase III trial (Z9001) that took five years to complete between 2002 and $2007 .{ }^{53}$ Eligible patients were those who had complete gross resection of GIST and tumors $\geq 3 \mathrm{~cm}$ in size. There was central pathological review and patients started treatment within 84 days of surgery; 713 patients were randomized and assigned to imatinib $400 \mathrm{mg} /$ day or placebo for one year. The initial primary endpoint was overall survival, which was subsequently amended to recurrence-free survival due to problems with the initial trial design. A statistically significant improvement in recurrence-free survival was seen during a median follow-up of 19.7 months, with an estimated one-year recurrence-free survival of $98 \%$ in the imatinib group versus $83 \%$ in the placebo group, with an overall hazard ratio of 0.35 (0.22-0.53 95\% confidence interval; $P<0.0001)$. In an unplanned subset analysis, it was shown that tumor size, particularly over $10 \mathrm{~cm}$, was an independent predictor of benefit from adjuvant imatinib. Patients were not stratified according to tumor site or mitotic rate, the latter because the technique for measuring mitotic rate was not standardized at that time. Of the patients who stopped treatment prematurely, those in the imatinib group were more likely to stop due to adverse events whereas those in the placebo group were more likely to stop due to tumor recurrence. Interestingly, the rate of recurrence in patients in the imatinib group was seen to increase six months after stopping adjuvant treatment, suggesting benefit from longer treatment with imatinib. Overall survival in both groups was similar, and likely to be due to the fact that crossover to the active drug was allowed upon disease recurrence. This pivotal study led to approval of use of imatinib for one year in high-risk patients.

At the same time as the US study are two further Phase III adjuvant imatinib studies, ie, the EORTC 62024 study, which randomized no treatment versus two years of adjuvant imatinib and is due to be reported later this year, and the Scandinavian Sarcoma Group's XVIII/AIO trial. This latter study was a collaboration between Scandinavian and German investigators and explored the effects of adjuvant imatinib in patients with high-risk GIST (modified National Institute of Health consensus criteria) given for one year versus three years. The trial took four years to recruit 400 patients between 2004 and 2008, with 200 in each arm and a median follow-up of 54 months. ${ }^{54}$ Patients in the three-year arm had both a significant improvement in relapse-free survival compared with the one-year arm (five-year survival $65.6 \%$ versus $47.9 \%$, respectively; $P<0.001)$ and longer overall survival (92\% versus $81.7 \%$ respectively; $P<0.02$ ). Subgroup analysis demonstrated that GIST patients with exon 11 mutation of $c$-KIT derived benefit from three years of adjuvant imatinib but those with exon 9 or PDGFRA mutation did not; however, numbers in these two latter groups were small. This landmark study has led to the adoption of three years of adjuvant imatinib as the recommended duration of treatment. ${ }^{55}$ However, there are a number of outstanding questions that require further investigation.

First, GIST mutational status appears to be important, and there is a consensus that patients with the imatinib-insensitive D842V mutation of PDGFRA should not receive adjuvant imatinib. ${ }^{56}$ What is less clear is whether patients with the exon 9 mutation should be treated with high-dose $(800 \mathrm{mg} /$ day $)$ imatinib analogous to that recommended in the advanced setting. Second, opinions are split with regard to the rare wild-type GIST subgroup. Third, there is the issue of whether patients who fall into the intermediate-risk group should be offered adjuvant therapy and what improvements can be made to risk stratification. Finally, the trial data clearly support three years of adjuvant imatinib over one year but should the treatment duration be longer? We know from the BFR-14 trial in patients with advanced GIST that some patients who had a complete response to imatinib but then had interrupted therapy relapsed even after five years of treatment (see section on Prolongation of imatinib treatment by intermittent dosing). This may suggest the persistence of an as yet unidentified imatinib-resistant GIST cancer stem cell population. ${ }^{57}$ The theoretical rationale for extending adjuvant imatinib beyond three years is counterbalanced by the possible development of imatinib-resistant mutations that would limit the efficacy of future therapies. There is a non-randomized Phase II trial of five years of adjuvant imatinib therapy currently in accrual (NCT00867113), which may help to define the optimal treatment duration for adjuvant imatinib.

\section{Neoadjuvant/preoperative imatinib}

The goal of neoadjuvant imatinib is to reduce the size of locally advanced GIST. This in turn may improve the likelihood of complete resection, reduce the risk of intraoperative complications including tumor rupture, reduce operative morbidity, improve the chance of function-sparing surgery, and hopefully improve long-term outcomes. Candidates for such treatment may include those with challenging anatomical locations, eg, rectal, duodenal, and esophageal GIST, and those with larger tumor sizes. Decisions surrounding preoperative imatinib should be made on a case-by-case basis and be taken in the multidisciplinary setting. Preoperative biopsy should be utilized not only to confirm the diagnosis 
of GIST but also to ensure that the imatinib-resistant D842V mutation is not present.

There are few prospective data on the use of imatinib in the preoperative setting. The use of neoadjuvant imatinib was retrospectively analyzed as part of the larger aforementioned prospective BFR-14 study, ${ }^{58}$ where 25 of 434 patients taking part in the study were identified to have a median tumor size of $15 \mathrm{~cm}$ with no metastatic disease and no prior surgery. Of these patients, 15 had a partial response (60\%) following treatment with imatinib for a median of four (range 1.4-12.8) months and nine patients went on to surgery after a median of seven (range 3.4-12) months. Outcomes in patients who had surgery following preoperative imatinib were comparable with those with localized intermediate and high-risk GIST in the subgroup of operated patients; whereas those who did not undergo surgery behaved similarly to those with metastatic GIST. Caveats do apply, given that this is a retrospective analysis and selection bias is a concern. Further, patients who responded well to imatinib were more likely to be able to proceed to surgery than those who did not.

In 2009, a Phase II trial from the US evaluating the role of neoadjuvant imatinib was reported. ${ }^{59}$ There were two groups of patients; those with primary GIST $(n=30)$ with a median tumor size of $9 \mathrm{~cm}$ and those with metastatic GIST. Patients were treated with neoadjuvant imatinib at a dose of $600 \mathrm{mg} /$ day for 8-12 weeks prior to surgery and then continued adjuvant imatinib $600 \mathrm{mg} /$ day for two years. Of these patients, 7\% had a partial radiological response and $83 \%$ had stable disease. Complete resection was performed in the localized GIST group in $77 \%$ of patients, and most had single organ resection. Two-year progression-free survival was $83 \%$ which compares well with data from the Phase III adjuvant imatinib study reported by the American College of Surgeons Oncology Group..$^{53}$ However, recently reported extended follow-up of this trial demonstrated that a high proportion of patients relapsed after two years of adjuvant imatinib. ${ }^{60}$ Following this, data from Canada were published on an open-label single-arm prospective Phase II study of imatinib $400 \mathrm{mg} /$ day in patients with locally advanced or metastatic GIST which was potentially resectable. ${ }^{61}$ Patients received imatinib for a maximum of 12 months to maximal tumor response, during which time there was the option of escalating the dose to $600 \mathrm{mg} /$ day at week 7 if there was no evidence of radiological response. Of the 14 patients who took part, six had a partial response and eight had stable disease with no evidence of tumor progression. Eleven of these patients had complete resection at surgery. Seven patients had their imatinib dose increased to $600 \mathrm{mg}$ /day and the median duration of imatinib treatment was nine months. The authors concluded that at least 6-12 months of preoperative imatinib should be given. Further data on imatinib is eagerly awaited from the German APOLLON study which is investigating preoperative imatinib for six months, the preliminary results of which were reported at the annual meeting of the American Society of Clinical Oncology in 2012. ${ }^{62}$

It is our view that neoadjuvant imatinib should be continued until maximum tumor response as demonstrated by cessation of tumor shrinkage on radiological assessment. In order to identify the time point of maximal response, frequent radiological assessments should be made, initially after one month to demonstrate imatinib sensitivity and threemonthly thereafter. It would seem from the available data that the optimum duration of treatment lies between six and 12 months. Unanswered questions include whether patients with exon 9 mutation should be given imatinib $800 \mathrm{mg} /$ day, and the duration for which adjuvant treatment should be given when neoadjuvant has already been used is uncertain, but three years in total seems rational. ${ }^{63}$

\section{Patient compliance and imatinib toxicity}

An important patient factor when considering the optimal duration of imatinib therapy is compliance with treatment and issues affecting adherence. Whatever the indication, imatinib is usually used for prolonged periods of time, and may be regarded as a treatment for chronic disease. In order to optimize patient outcomes and allow long-term treatment with imatinib, the associated toxicities of treatment should be managed proactively. It is notable that a considerable number of patients taking part in clinical trials of imatinib in both the adjuvant and metastatic setting have discontinued treatment due to toxicity. In the SSGXVIII study, just over 25\% of patients randomized to the three-year arm discontinued imatinib compared with $12.6 \%$ of patients in the one-year arm. Grade 3 or 4 events occurred in a third of patients and $13.6 \%$ of patients in the three-year arm discontinued imatinib due to adverse events. ${ }^{54}$ This clearly demonstrates that prompt management of side effects, prudent dose modifications, and continued patient support whilst on imatinib are of vital importance in order to optimize long-term outcomes. Further, it is noteworthy that patients who take part in clinical trials are in general a well motivated group and may not be representative of the general population. Treatment of an unselected group of patients with chronic myeloid leukemia using imatinib showed adherence rates $<90 \%$ in $26 \%$ of patients; moreover, $14 \%$ had adherence rates lower than $80 \%{ }^{64}$ 
Common toxicities associated with imatinib include diarrhea, fatigue, skin rash, and edema, and there is evidence that the worst toxicities arise in the first 3-6 months of treatment, in part due to alterations in pharmacokinetics over time. ${ }^{18,28}$ Changes in pharmacokinetics may also account for the differences in toxicity seen between men and women and also for the increased toxicity observed in older patients. Certainly if toxicity is unexpectedly severe in an individual patient, there may be a role for therapeutic drug monitoring. There is also a dose relationship, with side effects being more severe and frequent in patients treated with high-dose imatinib, ie, $>400 \mathrm{mg} /$ day. Optimizing the management of side effects includes effective patient information and engagement, including user-friendly advice on medicines that may alleviate the most common side effects. Input from specialist nurses who are readily available to patients is critical. GIST support groups and the Internet are also valuable resources.

In terms of long-term safety information, imatinib has been in use in patients with GIST or chronic myeloid leukemia for over 10 years and been investigated in numerous rigorous clinical trials. In general, imatinib is a safe drug to use in the long term as confirmed in the study by Blanke et al in which follow-up was for a median 63 months. ${ }^{26}$ Concerns have been raised about the cardiotoxicity profile of imatinib. ${ }^{65}$ However, these have not been borne out in the clinical trial setting, where an excess of cardiac events compared with the general population has not been detected. Imatinib-related edema has also been raised as a possible factor contributing to cardiotoxicity, but this has not been explored in a prospective fashion. Clearly, further prospective studies with cardiology input are needed to answer this question. Pre-existing cardiac disease should not be seen as a contraindication to treatment, although careful monitoring is advised. Changes in bone metabolism associated with hypocalcaemia, hypophosphatemia and low bone mineral density have been documented, so monitoring of bone health should be considered ${ }^{66,67}$ Finally, although the mechanism is not well described, imatinib may also impact on glucose metabolism, with reports of symptomatic hypoglycemia. ${ }^{68} \mathrm{In}$ summary, imatinib has been shown to be safe and effective even when used over a prolonged period of time.

\section{Summary}

Through a thorough understanding of the structure and function of c-KIT and its downstream signaling pathways combined with knowledge of the efficacy and tolerability of imatinib from clinical trial data, we will hopefully be able to maximize the benefit of imatinib in patients with GIST. The evidence thus far demonstrates that the duration of imatinib therapy should be as long as possible in the metastatic setting, providing that the patient is still responding to treatment. Data in the early disease setting is less mature, but points to at least three years of adjuvant imatinib in order to optimize patient outcomes. Further research is required to enhance our understanding of this rare disease.

\section{Acknowledgment}

We would like to thank the Royal Marsden National Institute for Health Research Biomedical Research Centre for supporting this research.

\section{Disclosure}

The authors report no conflicts of interest in this work.

\section{References}

1. Gatta G, van der Zwan JM, Casali PG, et al. Rare cancers are not so rare: the rare cancer burden in Europe. Eur J Cancer. 2011;47(17): 2493-2511.

2. Druker BJ, Talpaz M, Resta DJ, et al. Efficacy and safety of a specific inhibitor of the BCR-ABL tyrosine kinase in chronic myeloid leukemia. N Engl J Med. 2001;344(14):1031-1037.

3. Druker BJ, Tamura S, Buchdunger E, et al. Effects of a selective inhibitor of the Abl tyrosine kinase on the growth of Bcr-Abl positive cells. Nat Med. 1996;2(5):561-566.

4. Heinrich MC, Griffith DJ, Druker BJ, Wait CL, Ott KA, Zigler AJ. Inhibition of c-kit receptor tyrosine kinase activity by STI 571, a selective tyrosine kinase inhibitor. Blood. 2000;96(3):925-932.

5. Tuveson DA, Willis NA, Jacks T, et al. STI571 inactivation of the gastrointestinal stromal tumor c-KIT oncoprotein: biological and clinical implications. Oncogene. 2001;20(36):5054-5058.

6. Joensuu H, Roberts PJ, Sarlomo-Rikala M, et al. Effect of the tyrosine kinase inhibitor STI571 in a patient with a metastatic gastrointestinal stromal tumor. N Engl J Med. 2001;344(14):1052-1056.

7. Besmer P, Murphy JE, George PC, et al. A new acute transforming feline retrovirus and relationship of its oncogene v-kit with the protein kinase gene family. Nature. 1986;320(6061):415-421.

8. Yarden Y, Kuang WJ, Yang-Feng T, et al. Human proto-oncogene c-kit: a new cell surface receptor tyrosine kinase for an unidentified ligand. EMBO J. 1987;6(11):3341-3351.

9. DiNitto JP, Deshmukh GD, Zhang Y, et al. Function of activation loop tyrosine phosphorylation in the mechanism of c-Kit auto-activation and its implication in sunitinib resistance. J Biochem. 2010;147(4): 601-609.

10. Mol CD, Lim KB, Sridhar V, et al. Structure of a c-kit product complex reveals the basis for kinase transactivation. J Biol Chem. 2003;278(34): 31461-31464.

11. Mol CD, Fabbro D, Hosfield DJ. Structural insights into the conformational selectivity of STI-571 and related kinase inhibitors. Curr Opin Drug Discov Devel. 2004;7(5):639-648.

12. Mol CD, Dougan DR, Schneider TR, et al. Structural basis for the autoinhibition and STI-571 inhibition of c-Kit tyrosine kinase. J Biol Chem. 2004;279(30):31655-31663.

13. Lennartsson J, Ronnstrand L. Stem cell factor receptor/c-Kit: from basic science to clinical implications. Physiol Rev. 2012;92(4): 1619-1649.

14. Roskoski R Jr. Signaling by Kit protein-tyrosine kinase - the stem cell factor receptor. Biochem Biophys Res Commun. 2005;337(1):1-13. 
15. Jahn T, Seipel P, Urschel S, Peschel C, Duyster J. Role for the adaptor protein Grb10 in the activation of Akt. Mol Cell Biol. 2002;22(4): 979-991.

16. van Oosterom AT, Judson I, Verweij J, et al. Safety and efficacy of imatinib (STI571) in metastatic gastrointestinal stromal tumours: a Phase I study. Lancet. 2001;358(9291):1421-1423.

17. Demetri GD, von Mehren M, Blanke CD, et al. Efficacy and safety of imatinib mesylate in advanced gastrointestinal stromal tumors. $N$ Engl J Med. 2002;347(7):472-480.

18. Verweij J, van Oosterom A, Blay JY, et al. Imatinib mesylate (STI-571 Glivec, Gleevec) is an active agent for gastrointestinal stromal tumours, but does not yield responses in other soft-tissue sarcomas that are unselected for a molecular target. Results from an EORTC Soft Tissue and Bone Sarcoma Group Phase II study. Eur J Cancer. 2003;39(14): 2006-2011.

19. Verweij J, Casali PG, Zalcberg J, et al. Progression-free survival in gastrointestinal stromal tumours with high-dose imatinib: randomised trial. Lancet. 2004;364(9440):1127-1134.

20. Blanke CD, Rankin C, Demetri GD, et al. Phase III randomized, intergroup trial assessing imatinib mesylate at two dose levels in patients with unresectable or metastatic gastrointestinal stromal tumors expressing the kit receptor tyrosine kinase: S0033. J Clin Oncol. 2008;26(4):626-632

21. Casali PG, Verweij J, Kotasek D, et al. Imatinib mesylate in advanced gastrointestinal stromal tumors (GIST): survival analysis of the intergroup EORTC/ISG/AGITG randomized trial in 946 patients. Eur $J$ Cancer Suppl. 2005;3(2):201-202.

22. Gastrointestinal Stromal Tumor Meta-Analysis Group (MetaGIST). Comparison of two doses of imatinib for the treatment of unresectable or metastatic gastrointestinal stromal tumors: a meta-analysis of 1,640 patients. J Clin Oncol. 2010;28(7):1247-1253.

23. Pierotti MA, Tamborini E, Negri T, Pricl S, Pilotti S. Targeted therapy in GIST: in silico modeling for prediction of resistance. Nat Rev Clin Oncol. 2011;8(3):161-170.

24. Tamborini E, Pricl S, Negri T, et al. Functional analyses and molecular modeling of two c-Kit mutations responsible for imatinib secondary resistance in GIST patients. Oncogene. 2006;25(45):6140-6146.

25. Zalcberg JR, Verweij J, Casali PG, et al. Outcome of patients with advanced gastro-intestinal stromal tumours crossing over to a daily imatinib dose of $800 \mathrm{mg}$ after progression on $400 \mathrm{mg}$. Eur J Cancer. 2005;41(12):1751-1757.

26. Blanke CD, Demetri GD, von Mehren M, et al. Long-term results from a randomized Phase II trial of standard- versus higher-dose imatinib mesylate for patients with unresectable or metastatic gastrointestinal stromal tumors expressing KIT. J Clin Oncol. 2008;26(4): 620-625.

27. Debiec-Rychter M, Sciot R, Le Cesne A, et al. KIT mutations and dose selection for imatinib in patients with advanced gastrointestinal stromal tumours. Eur J Cancer. 2006;42(8):1093-1103.

28. Judson I, Ma P, Peng B, et al. Imatinib pharmacokinetics in patients with gastrointestinal stromal tumour: a retrospective population pharmacokinetic study over time. EORTC Soft Tissue and Bone Sarcoma Group. Cancer Chemother Pharmacol. 2005;55(4):379-386.

29. Demetri GD, Wang Y, Wehrle E, et al. Imatinib plasma levels are correlated with clinical benefit in patients with unresectable/metastatic gastrointestinal stromal tumors. J Clin Oncol. 2009;27(19):3141-3147.

30. Eechoute K, Fransson MN, Reyners AK, et al. A long-term prospective population pharmacokinetic study on imatinib plasma concentrations in GIST patients. Clin Cancer Res. 2012;18(20):5780-5787.

31. Bartolovic K, Balabanov S, Hartmann U, et al. Inhibitory effect of imatinib on normal progenitor cells in vitro. Blood. 2004;103(2):523-529.

32. Druker BJ, Guilhot F, O'Brien SG, et al. Five-year follow-up of patients receiving imatinib for chronic myeloid leukemia. $N$ Engl J Med. 2006;355(23):2408-2417.

33. Song MK, Chung JS, Seol YM, et al. Mean cell volume can be an early predictor for the cytogenetic response of chronic myeloid leukemia patients treated with imatinib? Leuk Res. 2009;33(11):1459-1462.
34. Constantinidou A, Krikelis D, Olmos D, et al. Early assessment of MCV to predict clinical outcome in patients with advanced gastrointestinal stromal tumors (GIST) receiving imatinib. J Clin Oncol. 2012;30 Suppl:S10086.

35. Le Cesne A, Ray-Coquard I, Bui BN, et al. Discontinuation of imatinib in patients with advanced gastrointestinal stromal tumours after 3 years of treatment: an open-label multicentre randomised Phase 3 trial. Lancet Oncol. 2010;11(10):942-949.

36. Patrikidou A, Chabaud S, Ray-Coquard I, et al. Influence of imatinib interruption and rechallenge on the residual disease in patients with advanced GIST: results of the BFR14 prospective French Sarcoma Group randomised, Phase III trial. Ann Oncol. 2013;24(4):1087-1093.

37. Conley AP, Araujo D, Ludwig J, et al. A randomized Phase II study of perifosine $(\mathrm{P})$ plus imatinib for patients with imatinib-resistant gastrointestinal stromal tumor (GIST) J Clin Oncol. 2009;27(Suppl 15): 10563.

38. Schoffski P, Reichardt P, Blay JY, et al. A Phase I-II study of everolimus (RAD001) in combination with imatinib in patients with imatinib-resistant gastrointestinal stromal tumors. Ann Oncol. 2010;21(10):1990-1998.

39. Demetri GD, Le-Cesne A, von Mehren M, et al. Final results form a Phase III study of IPI-504 (retaspimycin hydrochloride) versus placebo in patients (pts) with gastrointestinal stromal tumors (GIST) following failure of kinase inhibitor therapies. Abstract presented at the Gastrointestinal Cancers Symposium, Orlando, FL, January 22-24, 2010.

40. Wagner AJ, Morgan JA, Chugh R, et al. Inhibition of heat shock protein 90 (Hsp90) with the novel agent IPI-504 in metastatic GIST following failure of tyrosine kinase inhibitors (TKIs) or other sarcomas: clinical results from Phase I trial. J Clin Oncol. 2008;26(Suppl 15):10503.

41. Bauer S, Hilger R, Grabellus F, et al. Phase I trial of panobinostat (P) and imatinib (IM) in patients with treatment-refractory gastrointestinal stromal tumors (GIST). J Clin Oncol. 2012;30 Suppl:10032.

42. Raut CP, Posner M, Desai J, et al. Surgical management of advanced gastrointestinal stromal tumors after treatment with targeted systemic therapy using kinase inhibitors. J Clin Oncol. 2006;24(15): 2325-2331.

43. Mussi C, Ronellenfitsch U, Jakob J, et al. Post-imatinib surgery in advanced/metastatic GIST: is it worthwhile in all patients? Ann Oncol. 2010;21(2):403-408.

44. Al-Batran SE, Hartmann JT, Heidel F, et al. Focal progression in patients with gastrointestinal stromal tumors after initial response to imatinib mesylate: a three-center-based study of 38 patients. Gastric Cancer. 2007;10(3):145-152.

45. Demetri GD, van Oosterom AT, Garrett CR, et al. Efficacy and safety of sunitinib in patients with advanced gastrointestinal stromal tumour after failure of imatinib: a randomised controlled trial. Lancet. 2006;368(9544):1329-1338.

46. Jones RL, McCall J, Adam A, et al. Radiofrequency ablation is a feasible therapeutic option in the multi modality management of sarcoma. Eur J Surg Oncol. 2010;36(5):477-482.

47. Dileo P, Randhawa R, Vansonnenberg E, et al. Safety and efficacy of percutaneous radio-frequency ablation (RFA) in patients (pts) with metastatic gastrointestinal stromal tumor (GIST) with clonal evolution of lesions refractory to imatinib mesylate (IM). J Clin Oncol. 2004;22(Suppl 14):9024.

48. Miettinen M, Lasota J. Gastrointestinal stromal tumors: review on morphology, molecular pathology, prognosis, and differential diagnosis. Arch Pathol Lab Med. 2006;130(10):1466-1478.

49. Fletcher CD, Berman JJ, Corless C, et al. Diagnosis of gastrointestinal stromal tumors: a consensus approach. Hum Pathol. 2002;33(5): 459-465.

50. Miettinen M, Lasota J. Gastrointestinal stromal tumors: pathology and prognosis at different sites. Semin Diagn Pathol. 2006;23(2):70-83.

51. Gold JS, Gonen M, Gutierrez A, et al. Development and validation of a prognostic nomogram for recurrence-free survival after complete surgical resection of localised primary gastrointestinal stromal tumour: a retrospective analysis. Lancet Oncol. 2009;10(11):1045-1052. 
52. Joensuu H, Vehtari A, Riihimaki J, et al. Risk of recurrence of gastrointestinal stromal tumour after surgery: an analysis of pooled population-based cohorts. Lancet Oncol. 2012;13(3):265-274.

53. Dematteo RP, Ballman KV, Antonescu CR, et al. Adjuvant imatinib mesylate after resection of localised, primary gastrointestinal stromal tumour: a randomised, double-blind, placebo-controlled trial. Lancet. 2009;373(9669):1097-1104.

54. Joensuu H, Eriksson M, Sundby Hall K, et al. One vs three years of adjuvant imatinib for operable gastrointestinal stromal tumor: a randomized trial. JAMA. 2012;307(12):1265-1272.

55. [No authors listed]. Gastrointestinal stromal tumors: ESMO clinical practice guidelines for diagnosis, treatment and follow-up. Ann Oncol. 2012;23 Suppl 7:vii49-vii55.

56. Casali PG, Fumagalli E, Gronchi A. Adjuvant therapy of gastrointestinal stromal tumors (GIST). Curr Treat Options Oncol. 2012;13(3): 277-284.

57. Chen J, Guo T, Zhang L, et al. CD133 and CD44 are universally overexpressed in GIST and do not represent cancer stem cell markers. Genes Chromosomes Cancer. 2012;51(2):186-195.

58. Blay JY, Le Cesne A, Ray-Coquard I, et al. Prospective multicentric randomized Phase III study of imatinib in patients with advanced gastrointestinal stromal tumors comparing interruption versus continuation of treatment beyond 1 year: the French Sarcoma Group. J Clin Oncol. 2007;25(9):1107-1113.

59. Eisenberg BL, Harris J, Blanke CD, et al. Phase II trial of neoadjuvant/ adjuvant imatinib mesylate (IM) for advanced primary and metastatic/ recurrent operable gastrointestinal stromal tumor (GIST): early results of RTOG 0132/ACRIN 6665. J Surg Oncol. 2009;99(1):42-47.

60. Wang D, Zhang Q, Blanke CD, et al. Phase II trial of neoadjuvant/ adjuvant imatinib mesylate for advanced primary and metastatic/ recurrent operable gastrointestinal stromal tumors: long-term follow-up results of Radiation Therapy Oncology Group 0132. Ann Surg Oncol. 2012;19(4):1074-1080.

61. Doyon C, Sideris L, Leblanc G, Leclerc YE, Boudreau D, Dube P. Prolonged therapy with imatinib mesylate before surgery for advanced gastrointestinal stromal tumor results of a Phase II trial. Int J Surg Oncol. 2012;2012:761576.

62. Hohenberger P, Langer C, Wendtner CM, et al. Neoadjuvant treatment of locally advanced GIST: results of APOLLON, a prospective, open label Phase II study in KIT- or PDGFRA-positive tumors. J Clin Oncol. 2012;30 Suppl:10031.

63. Reichardt P, Blay JY, Boukovinas I, et al. Adjuvant therapy in primary GIST: state-of-the-art. Ann Oncol. 2012;23(11):2776-2781.

64. Marin D, Bazeos A, Mahon FX, et al. Adherence is the critical factor for achieving molecular responses in patients with chronic myeloid leukemia who achieve complete cytogenetic responses on imatinib. J Clin Oncol. 2010;28(14):2381-2388.

65. Kerkela R, Grazette L, Yacobi R, et al. Cardiotoxicity of the cancer therapeutic agent imatinib mesylate. Nat Med. 2006;12(8):908-916.

66. Berman E, Nicolaides M, Maki RG, et al. Altered bone and mineral metabolism in patients receiving imatinib mesylate. $N$ Engl $J$ Med. 2006;354(19):2006-2013.

67. Berman E, Girotra M, Cheng C, et al. Effect of long term imatinib on bone in adults with chronic myelogenous leukemia and gastrointestinal stromal tumors. Leuk Res. 2013;37(7):790-794.

68. Hamberg P, de Jong FA, Boonstra JG, van Doorn J, Verweij J, Sleijfer S. Non-islet-cell tumor induced hypoglycemia in patients with advanced gastrointestinal stromal tumor possibly worsened by imatinib. $J$ Clin Oncol. 2006;24(18):e30-e31.

69. Lux ML, Rubin BP, Biase TL, et al. KIT extracellular and kinase domain mutations in gastrointestinal stromal tumors. Am J Pathol. 2000;156(3): 791-795.

70. Miettinen M, Lasota J. Gastrointestinal stromal tumors - definition, clinical, histological, immunohistochemical, and molecular genetic features and differential diagnosis. Virchows Arch. 2001;438(1): $1-12$.

71. Conca E, Miranda C, Col VD, et al. Are two better than one? A novel double-mutant KIT in GIST that responds to imatinib. Mol Oncol. March 21, 2013. [Epub ahead of print.]
72. Roskoski R Jr. Structure and regulation of Kit protein-tyrosine kinase - the stem cell factor receptor. Biochem Biophys Res Commun. 2005;338(3):1307-1315.

73. Conca E, Negri T, Gronchi A, et al. Activate and resist: L576P-KIT in GIST. Mol Cancer Ther. 2009;8(9):2491-2495.

74. Tamborini E, Bonadiman L, Greco A, et al. A new mutation in the KIT ATP pocket causes acquired resistance to imatinib in a gastrointestinal stromal tumor patient. Gastroenterology. 2004;127(1):294-299.

75. Duensing A, Medeiros F, McConarty B, et al. Mechanisms of oncogenic KIT signal transduction in primary gastrointestinal stromal tumors (GISTs). Oncogene. 2004;23(22):3999-4006.

76. Rossi F, Ehlers I, Agosti V, et al. Oncogenic Kit signaling and therapeutic intervention in a mouse model of gastrointestinal stromal tumor. Proc Natl Acad Sci U S A. 2006;103(34):12843-12848.

77. Baird K, Davis S, Antonescu CR, et al. Gene expression profiling of human sarcomas: insights into sarcoma biology. Cancer Res. 2005;65(20):9226-9235.

78. Francis P, Namlos HM, Muller C, et al. Diagnostic and prognostic gene expression signatures in 177 soft tissue sarcomas: hypoxia-induced transcription profile signifies metastatic potential. BMC Genomics. 2007;8:73.

79. Astolfi A, Nannini M, Pantaleo MA, et al. A molecular portrait of gastrointestinal stromal tumors: an integrative analysis of gene expression profiling and high-resolution genomic copy number. Lab Invest. 2010;90(9):1285-1294.

80. Li F, Growney J, Battalagine L, Qiu S, Manley P, Monahan J. The effect combining the KIT inhibitor imatinib with the PI3K inhibitor BKM120 or the dual PI3K/mTOR inhibitor BEZ235 on the proliferation of gastrointestinal stromal tumor cell lines. Abstract 2239 presented at the 103rd Annual Meeting of the American Association for Cancer Research, Chicago, IL, March 31-April 4, 2012.

81. Floris G, Wozniak A, Sciot R, et al. A potent combination of the novel PI3K inhibitor, GDC-0941, with imatinib in gastrointestinal stromal tumor xenografts: long-lasting responses after treatment withdrawal. Clin Cancer Res. 2013;19(3):620-630.

82. Chang BS, Yang T, Cibas ES, Fletcher JA. An in vitro cytologic assay for evaluation of the KIT signaling pathway in gastrointestinal stromal tumors. Mod Pathol. 2007;20(5):579-583.

83. Pantaleo MA, Nicoletti G, Nanni C, et al. Preclinical evaluation of KIT/ PDGFRA and mTOR inhibitors in gastrointestinal stromal tumors using small animal FDG PET. J Exp Clin Cancer Res. 2010;29:173.

84. Duensing A, Joseph NE, Medeiros F, et al. Protein kinase C theta (PKCtheta) expression and constitutive activation in gastrointestinal stromal tumors (GISTs). Cancer Res. 2004;64(15):5127-5131.

85. Ou WB, Zhu MJ, Demetri GD, Fletcher CD, Fletcher JA. Protein kinase $\mathrm{C}$-theta regulates KIT expression and proliferation in gastrointestinal stromal tumors. Oncogene. 2008;27(42):5624-5634.

86. Bauer S, Yu LK, Demetri GD, Fletcher JA. Heat shock protein 90 inhibition in imatinib-resistant gastrointestinal stromal tumor. Cancer Res. 2006;66(18):9153-9161.

87. Smyth T, Van Looy T, Curry JE, et al. The HSP90 inhibitor, AT13387, is effective against imatinib-sensitive and -resistant gastrointestinal stromal tumor models. Mol Cancer Ther. 2012;11(8):1799-1808.

88. Floris G, Debiec-Rychter M, Wozniak A, et al. The heat shock protein 90 inhibitor IPI-504 induces KIT degradation, tumor shrinkage, and cell proliferation arrest in xenograft models of gastrointestinal stromal tumors. Mol Cancer Ther. 2011;10(10):1897-1908.

89. Muhlenberg T, Zhang Y, Wagner AJ, et al. Inhibitors of deacetylases suppress oncogenic KIT signaling, acetylate HSP90, and induce apoptosis in gastrointestinal stromal tumors. Cancer Res. 2009;69(17): 6941-6950

90. Edris B, Willingham SB, Weiskopf K, et al. Anti-KIT monoclonal antibody inhibits imatinib-resistant gastrointestinal stromal tumor growth. Proc Natl Acad Sci U S A. 2013;110(9):3501-3506.

91. Heinrich MC, Corless CL, Blanke CD, et al. Molecular correlates of imatinib resistance in gastrointestinal stromal tumors. J Clin Ocol: Official Journal of the American Society of Clinical Oncology. Oct 10 2006;24(29):4764-4774. 


\section{Publish your work in this journal}

OncoTargets and Therapy is an international, peer-reviewed, open access journal focusing on the pathological basis of all cancers, potential targets for therapy and treatment protocols employed to improve the management of cancer patients. The journal also focuses on the impact of management programs and new therapeutic agents and protocols on
Dovepress

patient perspectives such as quality of life, adherence and satisfaction. The manuscript management system is completely online and includes a very quick and fair peer-review system, which is all easy to use. Visit http://www.dovepress.com/testimonials.php to read real quotes from published authors.

\footnotetext{
Submit your manuscript here: http://www.dovepress.com/oncotargets-and-therapy-journal
} 